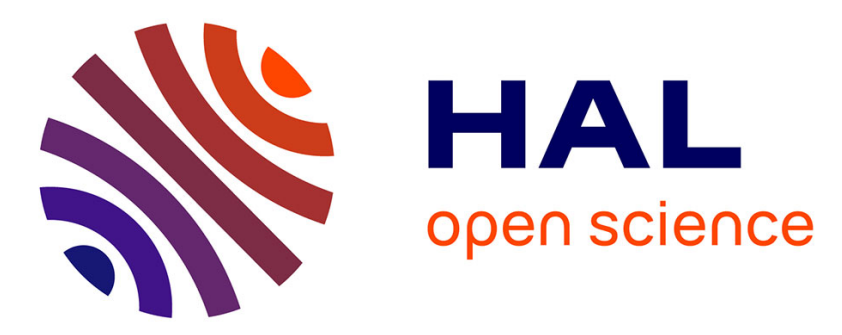

\title{
Understanding Customer Needs to Engineer Product-Service Systems
}

Fabiana Pirola, Giuditta Pezzotta, Daniela Andreini, Chiara Galmozzi, Alice Savoia, Roberto Pinto

\section{- To cite this version:}

Fabiana Pirola, Giuditta Pezzotta, Daniela Andreini, Chiara Galmozzi, Alice Savoia, et al.. Understanding Customer Needs to Engineer Product-Service Systems. IFIP International Conference on Advances in Production Management Systems (APMS), Sep 2014, Ajaccio, France. pp.683-690, 10.1007/978-3-662-44736-9_83 . hal-01387950

\section{HAL Id: hal-01387950 \\ https://inria.hal.science/hal-01387950}

Submitted on 26 Oct 2016

HAL is a multi-disciplinary open access archive for the deposit and dissemination of scientific research documents, whether they are published or not. The documents may come from teaching and research institutions in France or abroad, or from public or private research centers.
L'archive ouverte pluridisciplinaire HAL, est destinée au dépôt et à la diffusion de documents scientifiques de niveau recherche, publiés ou non, émanant des établissements d'enseignement et de recherche français ou étrangers, des laboratoires publics ou privés.

\section{(c)(1)}

Distributed under a Creative Commons Attribution| 4.0 International License 


\title{
Understanding customer needs to engineer Product- Service Systems
}

\author{
Fabiana Pirola ${ }^{1}$, Giuditta Pezzotta ${ }^{1}$, Daniela Andreini ${ }^{2}$, \\ Chiara Galmozzi $^{3}$, Alice Savoia ${ }^{3}$, Roberto Pinto ${ }^{1}$ \\ ${ }^{1}$ CELS - Research Group on Industrial Engineering, Logistics and Service Operations, De- \\ partment of Engineering, University of Bergamo, Italy \\ (giuditta.pezzotta@unibg.it; fabiana.pirola@unibg.it; \\ roberto.pinto@unibg.it) \\ ${ }^{2}$ Department of Management, Economics and Quantitative Methods, University of Bergamo, \\ Italy (daniela .andreini@unibg.it) \\ ${ }^{3}$ ABB S.p.A., Sesto San Giovanni (Milano), Italy
}

\begin{abstract}
Starting from the 90s, an increasing number of companies have been starting to move from a product-centric perspective towards Product-ServiceSystem (PSS). In this context, suitable models, methods and tools to collect, engineer and embed in a single solution all the knowledge that meets or exceeds people's emotional needs and expectations are required. Despite that, only few authors have proposed methodologies that can be easily adopted by industrial companies to design and engineer a product-service solution starting from the customer needs. Thus, this paper focuses on the customer needs analysis and aims at proposing a methodology to support companies in identifying customer needs, representing the starting point to the engineering and/or reengineering of PSS offering and the related delivery processes. An industrial case study in ABB S.p.A. has been carried out in order to test the methodology.
\end{abstract}

Keywords: Product-Service System · Service engineering · customer needs · Persona model

\section{Introduction}

Starting from the 90s [1], an increasing number of companies have been enlarging their offers starting to provide services in addition to their products moving from a productcentric perspective towards Product-Service-System (PSS). This change was spurred by "a continuous strive to create new sources of value for the company, by either reactively fulfilling explicit requirements or proactively providing new integrated productservice solutions to the customer" [2].

The design and development of product-service solutions, along with the management of its whole lifecycle, require the implementation of suitable models, methods and tools for collecting, engineering and embedding in a single solution all the knowledge that meets or exceeds people's emotional needs and expectations [2,3]. In this context, Service Engineering (SE) has emerged as a discipline calling for the de-

adfa, p. 1, 2011.

(C) Springer-Verlag Berlin Heidelberg 2011 
sign and the development of an integrated product-service offering adding value to customers [5]. In spite of the great success of the $\mathrm{SE}$ as a discipline in the academic context, only few authors have proposed methodologies and tools, which can be easily adopted by industrial companies during the design of a product-service solution [4, $6,7]$.

In order to fill this gap, the SErvice Engineering Methodology (SEEM) has been developed [8] with the aim to support companies during the (re)engineering of product-service offerings. As depicted in Fig.1, the SEEM is divided into two main areas: the customer area and the company area. The former deals with the analysis of customer needs and of the current product-service offering(s). The latter, starting from the customer needs identified in the "customer area", aims at defining, through the process prototyping and validation phases, the service features and the delivery process that allows for the best trade-off between customer needs satisfaction and company performance. Once the new service is validated, the service offering is updated.

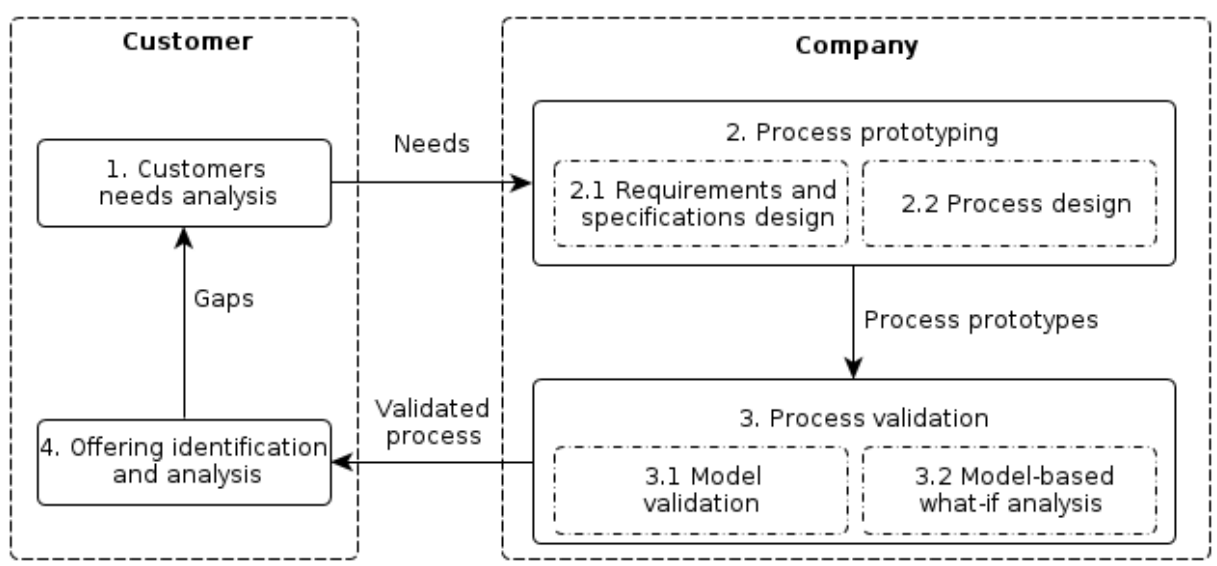

Fig. 1. The SErvice Engineering Methodology (SEEM) [9]

This paper focuses on the customer area of the SEEM and, in particular, on the "customer needs analysis" phase. In this area, the Persona Model (PM) is proposed as tool to collect and present information about customers [9]. This tool is based on Personas, fictional people describing the prototypical users of a product or service in terms of demographics and main values or needs. Thus, the objective of this paper is to propose a methodology to support companies in developing their customized customer needs list and therefore to build their Personas. These Personas are the company reference point when engineering and defining the service offering. In addition, an industrial case study in ABB S.p.A. has been carried out in order to test the methodology and to create the ABB Service Personas.

The reminder of the paper is structured as follows: section 2 presents a literature review on the persona model and on the main tools developed to gather customer values, section 3 introduces the proposed methodology, while section 4 presents the test and the implementation of the proposed methodology in ABB. Section 5 concludes the paper with final remarks and future development. 


\section{Persona model and customer needs}

Persona Model is a method useful for product and service development since it deals with the detailed design and representation of virtual users of the specific product or service $[9,10]$. This tool is based on Persona, which provides fictitious, specific and concrete representations of target users, based on real inputs and formally structured. It is composed of a demographic part with data related to age, gender, educational background, occupation, career and so on, and a narrative part, containing the type of individual that the persona is, what he likes and dislikes, skills, attitudes and decision states. It also includes a third part related to persona's specific needs or values and personal goals in the context of the service (or product) being designed. Some imaginary data (usually a name and a picture) are added to the description in order to provide product and service designers with a vivid representation of target users and to make the persona more tangible and alive. A Persona represents a customer segment.

PM is used in both Business to Consumer (B2C) and Business to Business (B2B) contexts. The main difference is that in B2C the Persona is composed of a list of value while in B2B of a list of needs. Values represent what individual desire and influence their actions. Values are "ideals" which individuals respect and believe in. On the other hand, needs represent a "deficiency state", something required or wanted, for which the individual feels a necessity to be satisfied. This difference is justified by the fact that in industrial situations individuals do not have the goal to achieve their ideals (as in B2C context) since they are interested in the satisfaction of their needs.

Regarding customer values, a first investigation of the literature shows that many researchers have tried to understand them and they have proposed methods to measure them accurately. The value term is used variously to refer to interests, pleasures, likes, preferences, duties, moral obligations, desires, wants, goals, needs, aversions and attractions. More precisely, values can be defined as cognitive representations of universal human requirements as biological needs, social interactional requirements and social institutional demands on the individual [11]. There are different ways to list and measure these values, the main ones are hereafter listed: Values, Attitudes and Lifestyles System (VALS) [12]; Rokeach's Value Survey (RSV) [13]; Schwartz [14]; List Of Values (LOV) [15] and SERPVAL scale [16]

All the above-mentioned lists refer to the value and they are all focused on B2C customers. From this analysis, it emerges that in B2B a defined default list of needs is still missing, even if there are several studies related to B2B needs. Thus, the aim of this paper is to propose a methodology to gather and analyze industrial customer needs and build industrial Personas, as presented in the next section.

\section{$3 \quad$ Methodology}

In order to overcome the main gap presented in literature, the objective of this paper is to propose a methodology to support companies in developing their customized customer needs list and therefore to build their Personas. This methodology will then be adopted in the SErvice Engineering Methodology (SEEM). The methodology (Fig. 
2) is structured as follows.

1. Qualitative interviews. They allow to collect insights about respondent views, experiences, beliefs and/or motivations and decision making process. Semi-structured interviews are adopted, therefore several key questions that help to identify interviewer's needs and decisional processes are defined. The flexibility of this approach allows the discovery or elaboration of information that may not have been previously thought from the research team. After the validation of the questionnaire, decision makers of customer companies are then interviewed face to face to identify their main needs and characteristics. The interviews, which are taperecorded, are detailed in a report and then analyzed by the research team. The main output of this step is the creation of a list of specific needs derived from the interviews.

2. Quantitative questionnaire. The main customers' needs arisen from Step 1 are utilized for building a specific questionnaire. This survey is structured in order to apply the MaxDiff methodology [17] to score the needs and identify which are the most important ones for the B2B customers. Reliability of the questionnaire is verified using a pilot test. Company performance according to these needs, structured with a five point rating scale (Likert-type scale), and customer features are also asked. An appropriate sample that represents the customer population is selected. The questionnaire is submitted to the customer's decision makers in the service area. Aim of this analysis is to get a representative sample of the company target market.

3. Analysis. All respondents' data are collected and statistically analyzed through the MaxDiff analysis [17]. The MaxDiff uses a sophisticated estimation technique to produce scores for each respondent on each item, the Hierarchical Bayes estimation (HB). The output of the tool is an estimation of scores related to each of all the fourteen needs, namely the rescaled (probability) scores. These positive values reflect the likelihood of items being chosen within the questionnaire. After that a cluster analysis is also performed to segment customer and therefore to identify the Personas. Each Persona defines a fictitious customer who represents the cluster and its characteristics. The definition of the Personas is fundamental in order to propose and engineer services able to satisfy different customers with different needs.
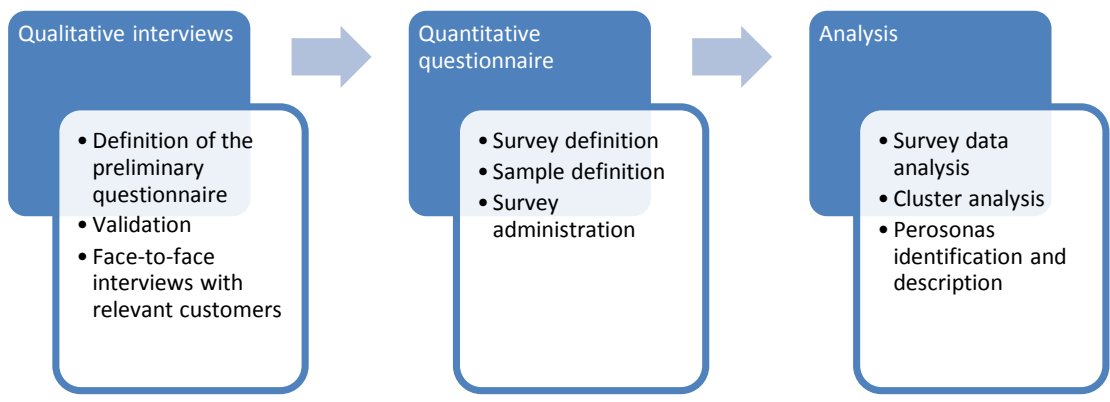

Fig. 2. Methodology 


\section{$4 \quad$ Case study}

$\mathrm{ABB}$ is one of the largest power and automation technology companies in the world. The company employs today 150.000 people all over the world and in 2013 had annual revenue of 42 billion of dollars.

The company operates in 5 divisions (Power Products, Power Systems, Discrete Automation and Motion, Low Voltage Products and Process Automation). This case study refers to the Italian Discrete Automation and Motion division, and in particular to Robotics, with the objective of creating $A B B$ Personas based on the needs of their industrial partners (called "customer" or "partner"). Their partners are system integrators (who install ABB products after having customized them) and OEM (suppliers with a large scope of provision that use $\mathrm{ABB}$ components only in a small percentage of final outputs). They represent the ABB direct customers but not the final customers of their solutions. Specifically, market segmentation will be conducted: customers will be grouped in different clusters in order to produce different $A B B$ Personas, providing a solid representation of target customers to be used during the definition of new services and update of the existing ones.

The implementation in the ABB context of the three above mentioned methodology steps in $\mathrm{ABB}$ is briefly described hereafter.

\subsection{Qualitative interviews}

Following a series of meetings and workshops with ABB experts in service, marketing and robotics, a semi-structured questionnaire based on open questions has been built and then validated.

Starting from general company characteristics, decision makers of customer companies are called to give their opinions regarding service in general and their experience, service management inside their company and their main objectives. Furthermore, a question regarding how much the service could affect the eventual choice of a supplier is posed to respondents. Concluding, an evaluation of ABB service is asked.

Combining all the needs emerged from respondents, the list of needs has been generated (see table 1 ). This list has been then used to build the quantitative questionnaire.

\subsection{Quantitative questionnaire}

After the definition of the customers' needs list and consulting the ABB Service and Marketing experts, a quantitative questionnaire has been designed. The questionnaire is structured in three main parts: the first section refers to the evaluation of customer's selection criteria when choosing a services supplier; the second section contains an evaluation of $\mathrm{ABB}$ performances and the last section is characterized by general questions about the company and its approach to service.

The questionnaire has been validated by an internal pilot test with two experts of the commercial area. Then, the survey has been conducted online and, in case of relevant partners, with face-to-face interviews. In total, 95 contacts (representative of 43 
different direct customers) have been defined: among these, 40 respondents fully completed the survey, with a $43 \%$ response rate.

\subsection{Analysis}

Once all answers have been collected, the first step has been to perform the MaxDiff analysis [17]. Thanks to this analysis, the customers' needs have been ranked on a scale from highest to lowest for each respondent. Table 1 reports for each analyzed need the average score of the sample.

Table 1. MaxDiff average score of the sample

\begin{tabular}{l|c}
\hline \multicolumn{1}{c|}{ Needs } & $\begin{array}{l}\text { Rescaled } \\
\text { Scores }\end{array}$ \\
\hline The supplier is fast in issue resolution & 16,95 \\
\hline The supplier has people with the right competences & 13,25 \\
\hline The supplier is able to answer customer request at any time and all over the world & 11,99 \\
\hline The supplier supports in reducing breakdown risks (or their impact) during warranty period & 11,25 \\
\hline The supplier is able to deliver spare parts in 24h all over the world & 9,33 \\
\hline The supplier is fair and cooperation is ruled by clear and transparent commercial terms & 7,05 \\
\hline The supplier is transparent (gives visibility) in programming interventions and reporting & 6,08 \\
\hline activities & 5,79 \\
\hline The supplier supports during engineering and commissioning period & 5,65 \\
\hline The supplier supports in offering services to end customers after warranty period & 3,28 \\
\hline The supplier has a low price & 2,99 \\
\hline The supplier trains my people for service purposes & 2,87 \\
\hline The supplier cooperates with us in service marketing and sales & 2,31 \\
\hline Maintenance of products is done by the manufacturer & 1,14
\end{tabular}

As emerged from the table, the needs receiving the highest scores are those ones related to the concepts of responsiveness and efficacy, customer assistance and availability of high-skilled personnel able to solve issues.

The least important need seems to be the reputation and the strong brand associated with the firm. This could be explained by the fact that when choosing a service provider the brand is not so relevant, while it is instead for the product (robot) itself.

Especially noteworthy is the score received by the need "The supplier has a low price": it has received a low score, even if is not in the bottom part of the ranking.

Once defined the score for each need, the cluster analysis has been adopted in order to segment customers and generate the Personas. In particular, a two-stage sequence of analysis has been applied:

1. A hierarchical cluster analysis using Ward's method and applying squared Euclidean Distance has been chosen to determine the optimum number of clusters. Ward's method uses an analysis of variance approach to evaluate the distances be- 
tween clusters. The Ward's method has been selected in this case because the analyzed dataset do not include any outliers [18];

2. The hierarchical cluster analysis has been re-run with the selected number of clusters. This second step has allowed the allocation of each case to a particular cluster.

As result, the following three ABB Personas have been identified:

- Persona 1, representative of cluster 1, is a young technician with some years of experience, working in a big company (specifically, a system integrator). He needs spare parts in short time and requires fast issue resolution.

- Persona 2, representative of cluster 2, is the owner of a big company operating as a system integrator. He has a lot of experience in the field. He takes for granted common service needs and focuses on high-level needs: he is interested in a partnership with $\mathrm{ABB}$, asking for a strong partnership and cooperation with supplier.

- Persona 3, representative of cluster 3, is a mechanical engineer working in a small OEM company. He is a young man that requires constant support from ABB since he has not all the right competences.

\section{Conclusions}

This paper has provided a deep understanding of customers' needs, as required in the first phase of the SErvice Engineering Methodology (SEEM), highlighting the importance of a customer-centred approach as the starting point in the service engineering process. To this purpose, the Persona Model is used to gather and represent the main product-service users, in terms of demographic features, personal characteristics and needs. Thanks to the literature review, different lists of values emerge related to the B2C contexts, while in the B2B industrial context a similar list of needs is missing. Thus, since in the $\mathrm{B} 2 \mathrm{~B}$ context each single case has to be considered as unique, a structured methodology to define a list of needs in the Persona Model have been proposed. In addition, to test the validity and applicability an industrial case study in ABB has been provided. This has allowed to generate the list of industrial customer needs and therefore to segment them in different clusters and identify three customer Personas on which the service offering should be engineered.

The main limitation of this work, however, is represented by the difficulty to generalize the list of the industrial customers' needs, since they are strongly linked to the specific industrial reality. In order to have more robust results, it would be optimal to have a higher number of respondents. For this reason, future developments will be to improve the analysis considering much more respondents and add other variables useful for the description of the clusters.

Acknowledge. The research leading to these results has received funding from ABB S.p.A Italy. 


\section{References}

1. Vandermerwe, S., Rada, J.: Servitization of Business: Adding Value by Adding Services. Eur. Manage J., 6(4), 314-324 (1988)

2. Cavalieri, S., Pezzotta, G. (2012).: Product-Serice Systems Engineering: State of the art and research challenges. Comput. Ind. 63, 278-288 (2012)

3. Berry. L.L., Carbone L.P., Haeckel S.H.: Managing the Total Customer Experience. MIT Sloan Management Review. Spring, 85-90 (2002)

4. Cavalieri, S., Pezzotta, G., Shimomura, Y.: Product-service system engineering: From theory to industrial applications. Comput. Ind. 63, 275-277 (2012)

5. Bullinger, H.J., Fahnrich, K.P., MeirenT.: Service engineering-methodical development of new service products. Int. J. Prod. Econ. 85(3), 275-287 (2003)

6. Rapaccini M, Saccani N, Pezzotta G, Burger T, Ganz W.: Service development in productservice systems: a maturity model. Serv. Ind. J. 33(3-4), 300-319 (2013).

7. Shimomura Y, Tomiyama T.: Service modeling for service engineering. In: Arai E, Fumihiko K, Goossenaerts J, Shirase K editors. Knowledge and Skill Chains in Engineering and Manufacturing. Springer, 31-38 (2005)

8. Pezzotta, G., Pinto,R., Pirola,F., Ouertani, M.: Balancing Product-Service Provider's Performance and Customer's Value: the SErvice Engineering Methodology (SEEM). In: 6th CIRP Conference on Industrial Product-Service Systems (2014)

9. Pruitt, J., Adlin, T.: The Persona Lifecycle: Keeping People in Mind Throughout Product Design. Morgan Kaufmann (2006)

10. Y. Shimomura, Y., Hosono, S., Hasegawa, M., Hara, T., Arai, T.: A Methodology of Persona-centric Service Design. In: $19^{\text {th }}$ CIRP Design Conference - competitive Design, Cranfield, UK (2009)

11. Kamakura, W. A., Novak, T. P.: Value-System Segmentation: Exploring the Meaning of LOV. J. Consum. Res. 19(1), 119-132 (1992)

12. Vincent, T., Selvarani, D.: Personal Values Approach For A Better Understanding Of Consumer Behaviour. Int. J. Innov. Res. Dev. 2(3), 509-517 (2013)

13. Vinson, D. E., Munson, J., Nakanishi, M.: An Investigation of the Rokeach Value Survey For Consumer Research Applications. Adv. Consum. Res. 4(1), 247-252 (1977)

14. Schwartz, S. H.: Universals in the content and structure of values: theoretical advances and empirical tests in 20 countries. In: Zanna, M.P. Advances in experimental social psychology, Elsevier, 25, 1-65 (1992)

15. Kahle, L. R., Beatty, S. E., Homer, P.: Alternative Measurement Approaches to Consumer Values: The List of Values (LOV) and Values and Life Style (VALS). J. Consum. Res. 13(3), 405-409 (1986)

16. Lages, L. F., Fernandes, J. C.: The SERPVAL scale: a multi-item instrument for measuring service personal values. J. Bus. Res. 58, 1562-1572 (2005)

17. Almquist, E., Lee, J.: What Do Customers Really Want?. Harvard Bus. Rev. 3, (2009)

18. Ward Jr, Joe H.: Hierarchical grouping to optimize an objective function, J. Am. Stat. Assoc., 58(301), 236-244 (1963) 